\section{Current concepts in the diagnosis, pathogenesis and management of nonarteritic anterior ischaemic optic neuropathy}

\begin{abstract}
Nonarteritic anterior ischaemic optic neuropathy (NAION) is the most common acute optic neuropathy in patients over the age of 50 and is the second most common cause of permanent optic nerve-related visual loss in adults after glaucoma. Patients typically present with acute, painless, unilateral loss of vision associated with a variable visual field defect, a relative afferent pupillary defect, a swollen, hyperaemic optic disc, and one or more flame-shaped peripapillary retinal haemorrhages. The pathogenesis of this condition is unknown, but it occurs primarily in patients with structurally small optic discs that have little or no cup and a variety of underlying vascular disorders that may or may not be known at the time of visual loss. There is no consistently beneficial medical or surgical treatment for the condition, but there are now animal models that allow testing of various potential therapies. About $40 \%$ of patients experience spontaneous improvement in visual acuity. Patients in whom NAION occurs in one eye have a 15-19\% risk of developing a similar event in the opposite eye over the subsequent 5 years. Eye (2015) 29, 65-79; doi:10.1038/eye.2014.144; published online 4 July 2014
\end{abstract}

\section{Introduction}

Nonarteritic anterior ischaemic optic neuropathy (NAION) is the second most common optic neuropathy in adults. Although much is known regarding its clinical
NR Miller ${ }^{1}$ and AC Arnold ${ }^{2}$

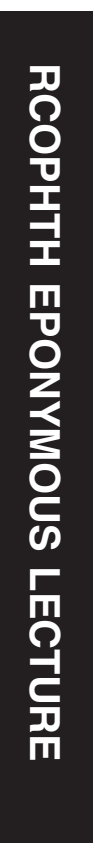

consistently effective treatment. In this paper, we will discuss what is and is not known about this condition.

\section{Demographics}

NAION is the most common acute optic neuropathy in patients over 50 years of age, with an estimated annual incidence in the United States of 2.3-10.2 per 100000 population, ${ }^{1,2}$ accounting for at least 6000 new cases annually. The disease occurs much more frequently in Caucasians than in those who identify themselves as African-American or Hispanic. $^{3}$ There is no gender predisposition. ${ }^{2-6}$ The mean age at onset in most studies ranges from 57 to 65 years. $^{2-6}$

\section{Clinical presentation}

NAION presents with loss of vision occurring over hours to days, often described as blurring, dimness, or cloudiness in the affected region of the visual field, most often inferiorly. Although Hayreh et $a l^{7}$ reported that visual loss was most frequently reported upon awakening, this feature was not confirmed in the Ischemic Optic Neuropathy Decompression Trial (IONDT). ${ }^{5}$ NAION typically presents without pain, although some form of periocular discomfort is reported in $8-12 \%$ of affected individuals. ${ }^{5,8}$ In contrast to patients with optic neuritis, those with NAION usually do not report pain with eye movement. The initial course may be static, with little or no fluctuation of visual level after initial loss, or progressive, with episodic,
'Department of Ophthalmology, The Wilmer Hopkins Hospital, Baltimore, MD, USA

${ }^{2}$ UCLA Department of Ophthalmology, The Jules Stein Eye Institute, Los Angeles, CA, USA

Correspondence: NR Miller, Department of Ophthalmology, The Wilmer Eye Institute, Johns Hopkins Hospital, Woods 458, 600 North Wolfe Street, Baltimore, MD 21287, USA

Tel: +1 410502 3213; Fax: +1 4105023214

E-mail: nrmiller@jhmi.edu

Received: 12 May 2014 Accepted: 13 May 2014 Published online: 4 July 2014 Eye Institute, The Johns 
stepwise decrements, or a steady decline of vision over days to weeks before eventual stabilization.

Visual acuity in patients with NAION varies considerably, from 6/6 to no perception of light; however, in general, the drop in acuity in patients with NAION is less than that experienced by patients with the arteritic form of AION, with over $50 \%$ of patients having acuity better than $6 / 60{ }^{4}$ Colour vision loss in NAION tends to parallel visual acuity loss, as opposed to that in optic neuritis, in which colour loss is often disproportionately greater than visual acuity loss. Visual field defects in NAION may follow any pattern related to optic nerve damage, but altitudinal loss, usually inferior, occurs in the majority (Figure 1), ranging from 55 to $80 \%$ of reported cases. $4,9,10$

The optic disc swelling that defines NAION may be diffuse or segmental and hyperaemic (Figure 2a) or pale, although pallid swelling occurs much less frequently than in the arteritic form. Peripapillary retinal haemorrhages are common, but soft exudates (ie, cottonwool spots) are unusual. A partial or complete macular star pattern of hard exudate is occasionally present, but its presence should suggest another condition, such as neuroretinitis. The retinal arterioles may be diffusely or focally narrowed, particularly in severe cases (Figure 3a). ${ }^{11}$ The optic disc in affected eyes (if seen before onset of NAION) as well as in the contralateral eye is typically small in diameter ${ }^{12,13}$ and demonstrates a small or absent physiologic cup (Figure 2b). ${ }^{14-16}$ This 'crowded' morphologic appearance is believed to predispose the optic nerve head to ischaemia because of presumed structural crowding of the approximately 1 million axons at the level of the lamina cribrosa and has therefore been described as a 'disc-at-risk' (see below). ${ }^{16}$

It is reasonable to assume that the onset of optic disc swelling is simultaneous with the beginning of visual symptoms; however, this may not always (?ever) be the case. Hayreh and Zimmerman ${ }^{17}$ described cases of 'incipient' NAION in which there is clear-cut typical optic disc swelling unassociated with any visual symptoms (Figure 3). They found that $55 \%$ of patients with this condition experience resolution of disc swelling without ever suffering visual loss, whereas $25 \%$ of patients become symptomatic, usually within several weeks, and $20 \%$ have resolution of disc swelling only to have it recur symptomatically weeks to months later. Arnold et al ${ }^{18}$ recently confirmed fluorescein angiographic evidence of filling delay consistent with impaired perfusion in a patient with this presymptomatic phase of NAION.

\section{Pathophysiology}

NAION is presumed to result from circulatory insufficiency within the optic nerve head, but the specific
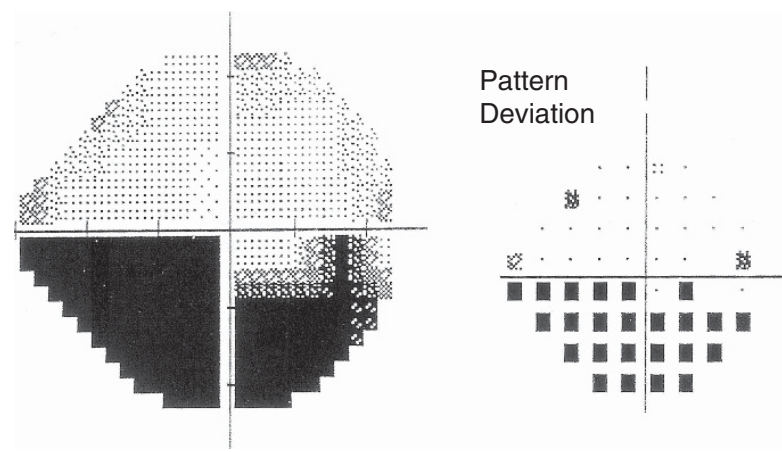

Figure 1 Typical inferior altitudinal/arcuate visual field defect in NAION.
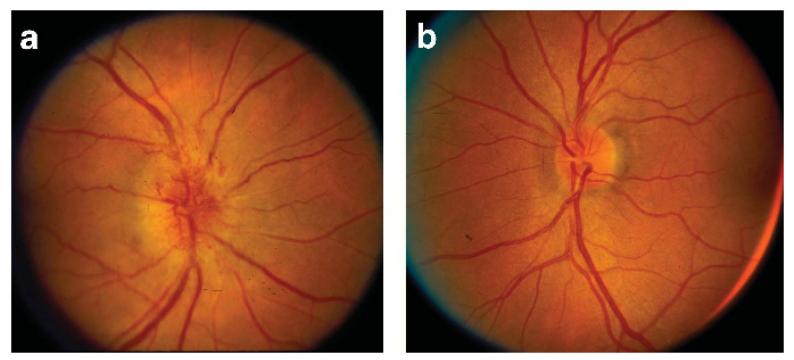

Figure 2 Appearance of affected and unaffected optic discs in a patient with NAION. a, optic disc in eye with NAION is swollen and hyperaemic. Note several peripapillary flame-shaped haemorrhages. $b$, optic disc in unaffected eye is small and has no cup.
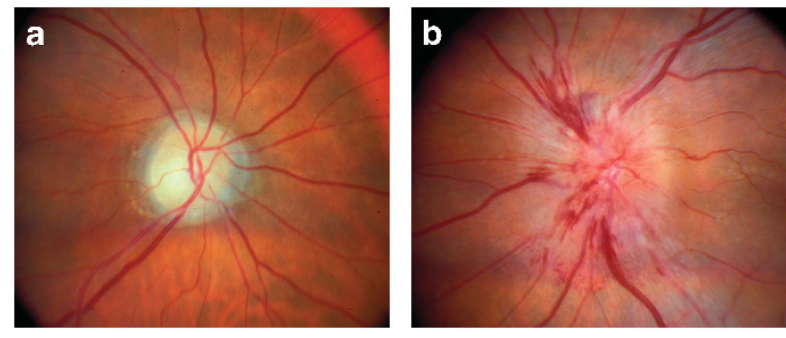

Figure 3 Patient with incipient NAION. The patient had previously experienced an attack of NAION in his right eye. He was seen for a routine evaluation. Vision in the right eye was $6 / 60$. He had no visual concerns with respect to his left eye. Left eye vision was $6 / 6$ and the field was full. a, the right optic disc is diffusely pale; it has no cup. The retinal arteries are diffusely and focally narrowed. b, the left optic disc is swollen and hyperaemic. There are multiple flame-shaped peripapillary haemorrhages present. The patient subsequently experienced visual loss in the eye about 1 week later.

location of the vasculopathy and its pathogenetic mechanism remain unproven. ${ }^{19}$ Although blood flow through the short posterior ciliary arteries (SPCAs) is reduced in patients with $\mathrm{NAION}^{20}$ the rare cases that have been studied histopathologically have shown no evidence of thrombosis of the SPCAs ${ }^{21,22}$ and it therefore 
is believed that the condition is due in some cases to generalized hypoperfusion and in others to occlusion of disc or laminar capillaries (see below). The lack of consistent choroidal filling delay in fluorescein angiography studies of NAION suggests that the impaired perfusion arises in the paraoptic tributaries of the SPCA's, distal to their split from the choroidal branches. ${ }^{23}$

\section{Pathogenesis}

The mechanisms involved in the development of optic disc ischaemia in NAION are unclear. Whether ischaemia results from local arteriosclerosis with or without thrombosis, embolization from a remote source, generalized hypoperfusion, vasospasm, failure of autoregulation, or some combination of these processes is not known. Indeed, even occlusion of the venous system has been proposed as a mechanism. ${ }^{24}$ Although structurally small, 'crowded' optic discs are associated with NAION, the mechanism by which this contributes to ischaemia has not been elucidated, and the role of additional factors such as nocturnal hypotension and sleep apnoea is unproven (see below) as large-scale epidemiologic studies have not been performed.

Whatever the cause for impaired blood flow in the optic nerve vasculature, persistent hypoperfusion requires impairment in the normal autoregulatory mechanisms of the optic nerve head. Flow normally is maintained constant with variations in perfusion pressure, intraocular pressure, and metabolic conditions (including tissue oxygen and $\mathrm{CO}_{2}$ levels) by factors that vary resistance to flow, such as autonomic input. These autoregulatory mechanisms may be impaired by arteriosclerosis, vasospasm, or medications, including beta-blockers and other antihypertensive medications.

As noted above, almost all patients who develop NAION have a 'disc-at-risk.' 16 The structure of the optic disc as a relatively inflexible region encompassing the axons of the optic nerve has been implicated in two histopathologic studies. Tesser et $a l^{25}$ reported that the infarct documented in their case did not follow a specific vascular territory, suggesting a compartment syndrome as a mechanism. Knox et $a l^{26}$ reviewed the histopathologic features in 193 eyes classified as having optic nerve ischaemia (without clinical correlation) in the Eye Pathology Laboratory of the Wilmer Eye Institute and accessioned from 1951 to 1998. Sixty-nine eyes (36\%) demonstrated cavernous degeneration within the laminar region. Those cases in which there was substantial compression of the adjacent axons by the expanding mucopolysaccharide cavern lend support to the compartment syndrome as a mechanism in at least some cases of NAION.

\section{Risk factors}

In addition to a 'disc-at-risk,' almost all patients who develop NAION have at least one underlying vascular risk factor that may or may not be known at the time they lose vision. For example, Hayreh believes that nocturnal systemic hypotension has a major role in the development of NAION. ${ }^{7}$ He has emphasized that the relative hypotension that normally occurs with sleep may chronically compromise optic disc circulation, particularly in patients with an exaggerated nocturnal 'dip' or in patients, such as those with systemic hypertension, in whom optic disc circulation autoregulatory mechanisms are impaired. This effect may be worsened with aggressive antihypertensive therapy, particularly if administered at night, by exacerbating the nocturnal pressure drop. Data supporting this hypothesis come from a study in which Hayreh et $\mathrm{al}^{7}$ performed 24-h ambulatory blood pressure monitoring in 52 subjects with NAION and compared the results with those from 19 patients with primary open-angle glaucoma (POAG) and 65 patients with 'normal-tension' glaucoma (NTG). Mean decreases in systolic and diastolic blood pressure of $25.3 \%$ and $31.2 \%$, respectively, were noted in NAION. As no controls were monitored, it remains unclear if this represents an exaggerated nocturnal drop in pressure. In general, no significant differences in pressure decrease were observed among NAION, NTG, and POAG; however, the $31.2 \%$ diastolic decrease in NAION was significantly less $(P=0.004)$ than the $36.0 \%$ figure for NTG. In patients with NAION with systemic hypertension on medication, nighttime blood pressure figures were significantly lower in those with visual field deterioration (progressive NAION, 25 of 42 patients). A subsequent report from the same investigators ${ }^{27}$ included a total of 114 NAION, 131 NTG, and 30 POAG subjects, presumably incorporating the prior study. Based on the total data, the authors suggested that nocturnal systemic hypotension has a significant role in the development of NAION in certain susceptible subjects.

Not everyone agrees that hypotension has a major role in the pathogenesis of NAION. Landau et al ${ }^{28}$ performed 24-h ambulatory blood pressure monitoring in 24 subjects with NAION and 24 age-, disease-, and medication-matched controls. Mean decreases of $11 \%$ systolic and $18 \%$ diastolic were measured in NAION, compared with $13 \%$ and $18 \%$, respectively, in controls, showing no significant difference. These investigators did, however, see mildly lower mean daytime pressures in NAION than controls, averaging $5-7 \mathrm{~mm} \mathrm{Hg}$; the largest difference was noted in the morning, indicating a slower morning rise in pressure in NAION subjects when compared with normal controls. The conflicting data 
from these two groups leave the role of nocturnal hypotension in NAION unresolved; however, we recommend a discussion with patients with NAION as well as with their physicians regarding the possible accentuation of nocturnal hypotension by nighttime use of anti-hypertension medications, and we recommend that they take their medication during the day rather than at bedtime.

NAION has been reported in association with many conditions that may predispose to decreased optic nerve head perfusion via microvascular occlusion (Table 1). For example, systemic hypertension has been documented in $34-49.4 \%$ of patients and diabetes mellitus in $5-25.3 \% .^{29-31}$ Diabetes is associated with the development of NAION at a younger age in most series as well. Hyperlipidaemia is also a common finding in patients with NAION. ${ }^{32,33}$ It is important to note, however, that in many patients who develop NAION, the underlying systemic vasculopathy is not known at the time that NAION occurs. A large-scale (137 cases) but uncontrolled study by Chung et al ${ }^{34}$ concluded that smoking was a significant risk factor on the basis that smokers developed NAION at a significantly younger age than nonsmokers.

Many people assume that the obstructive sleep apnoea syndrome (OSAS) only occurs in obese individuals; however, this is not the case. OSAS can occur in individuals who are neither obese nor overweight and has been reported to be present in up to $89 \%$ of patients who develop NAION, ${ }^{35-40}$ a much higher prevalence than in an age- and gender-matched population with similar other vascular risk factors (eg, diabetes mellitus, hypertension, and tobacco use). It is unclear, however, if OSA is causative or merely further evidence of vascular dysregulation. ${ }^{41} \mathrm{Li}$ et $a l^{37}$ reported in a case-control study that a validated questionnaire can be used to identify patients with NAION who also have OSAS; however, it is unclear if treatment of OSA with continuous positive airway pressure reduces the risk of first- or even secondeye involvement. ${ }^{42}$

Table 1 Risk factors associated with the development of spontaneous NAION

Hypotension (esp, nocturnal)
Hypertension
Diabetes mellitus
Hyperlipidaemia
Anaemia
Obstructive sleep apnoea
Hyperhomocysteinaemia
Various coagulopathies (eg, increased factor VIII)
Migraine
Smoking
Optic disc drusen
Cataract extraction (uncomplicated)

Hypotension (esp, nocturnal)

Hypertension

Various coagulopathies (eg, increased factor VIII)

Migraine

Optic disc drusen

Cataract extraction (uncomplicated)
Elevated plasma homocysteine levels are associated with an increased risk of premature ischaemic events (peripheral vascular disease, stroke, and myocardial infarction) in patients younger than 50 . The prevalence of hyperhomocysteinaemia in the general population is estimated at 5\%, a figure that increases to $20-30 \%$ in nondiabetic stroke or myocardial infarction patients younger than 55. The mechanism of vasculopathy related to hyperhomocysteinaemia is unclear. Although some severe cases are related to an inherited deficiency of methylenetetrahydrofolate reductase, resulting in decreased conversion of homocysteine to methionine, in others, poor intake or absorption of common vitamins B6, B12, and folic acid may impair the breakdown of homocysteine.

The relation of hyperhomocysteinaemia to NAION remains unclear. Although Pianka et al ${ }^{43}$ reported elevated levels in $45 \%$ of 40 NAION patients (mean age 66 years) vs $9.8 \%$ of controls, and Weger et al ${ }^{44}$ also reported mean elevation (11.8 vs $9.8 \mu \mathrm{mol} / \mathrm{l})$ in 59 NAION patients $v$ controls, Biousse et al ${ }^{45}$ reported normal values in 14/14 patients with a mean age of 43 years. The clinical significance of these statistically significant findings is uncertain, limited by small patient numbers and widely varying results $(0 / 14$ in Biousse et $a l^{45}$ to $45 \%$ in Pianka et $a l^{43}$ ).

Isolated reports have documented prothrombotic risk factors in patients with NAION, but a large-scale study by Salomon et $a^{30}$ did not confirm an association. These investigators evaluated risk factors for thrombosis, including lupus anticoagulants, anticardiolipin antibodies, prothrombotic polymorphisms (eg, factor $\mathrm{V}$ Leiden), and deficiencies of protein $C$ and $S$ and antithrombin III in a series of 61 patients with NAION vs 90 controls. No correlation with any of these factors was detected. Salomon et $a l^{46}$ also found no association of angiotensin-converting enzyme and angiotensin II type 1 receptor polymorphisms with NAION; however, Salomon et al ${ }^{47}$ subsequently compared 92 consecutive patients with NAION with 145 controls for evidence of platelet glycoprotein polymorphisms. They found a statistically significant association with the VNTR B allele in NAION vs controls; second-eye involvement was more frequent and earlier in onset in those with the polymorphism. These last data suggest that perhaps some previously undetected or neglected prothrombotic conditions are linked to the development of NAION; further investigation is required to establish definitively these and other associations.

NAION has been associated infrequently with a multitude of additional factors and disorders that may be causative, either due to optic disc structure or other features that may affect optic disc perfusion pressure. 
These include optic disc drusen, cataract surgery, migraine, and certain medications.

NAION may occur in patients with optic disc drusen. Purvin et $\mathrm{al}^{48}$ reviewed the clinical presentation in 24 eyes of 20 patients with NAION occurring in the setting of optic disc drusen. No unusual features were present aside from the substantially lower age group affected (mean age, 49.4 years, range 18-69). Vasculopathic risk factors were present in 50\%. Although it is reasonable to attribute early development of NAION in this patient group to an exaggerated contribution of optic disc 'crowding' due to the drusen, it is unclear why it remains a relatively rare occurrence.

Townes et $a l^{49}$ may have described the first cases of what is now called 'post-cataract extraction NAION' in the English literature in 1961 when they reported four patients who developed what they called 'optic neuritis' after apparently uncomplicated cataract surgery. Reese and Carroll ${ }^{50}$ subsequently reported post-cataract extraction 'optic neuritis' in 17 eyes of 17 patients. The loss of vision occurred 6-12 weeks after surgery, and all patients presented with a central scotoma and optic disc swelling in the affected eye. Ten of the 17 patients underwent cataract extraction in the fellow eye, and 3 developed a similar process in that eye. Michaels and Zugsmith ${ }^{51}$ emphasized that some patients with this condition experienced immediate visual loss whereas in others, visual loss occurred weeks to months after the surgery. Carroll ${ }^{52}$ subsequently published nine more cases. Between his initial series and the subsequent one, 8 of 17 patients $(47 \%)$ who experienced post-cataract extraction in one eye developed an identical process after cataract extraction in the fellow eye. McCulley et a ${ }^{53}$ reviewed 5787 cases of cataract extraction over a 5-year period and identified 3 cases of anterior optic neuropathy resembling NAION occurring within 1 year of the procedure (29, 36, and 117 days), with an overall incidence of 1 in 2000 and an estimated 6-month incidence of 51.8/100000, significantly higher than the reported overall incidence (see above). The association of post-cataract extraction anterior optic neuropathy was supported by a subsequent study by McCulley et $a l,{ }^{54}$ in which the temporal association of 18 cases occurring within 1 year following cataract surgery was compared with a uniform distribution; the finding that all 18 cases occurred within 6 months after surgery was statistically significant. Finally, Lam et a ${ }^{55}$ performed a retrospective cohort study in which they identified 325 patients who developed spontaneous NAION in one eye, 17 of whom underwent cataract extraction in the fellow eye. Of these 17 individuals, 9 (53\%) developed an anterior optic neuropathy in the fellow eye, with 6 of the 9 developing the condition within 6 months (median 2.8 months). Among the remaining 308 patients who had no cataract surgery in the eye contralateral to that which experienced spontaneous NAION, 59 (19\%) experienced spontaneous NAION in that eye. Using these data, Lam et al ${ }^{55}$ calculated that the risk of a post-cataract extraction anterior optic neuropathy was 3.6 times higher in patients who had experienced an attack of spontaneous NAION in the other eye compared with patients who had not had an attack of spontaneous NAION and concluded that the anterior optic neuropathy that occurs shortly after uncomplicated cataract extraction is, indeed, a form of NAION.

NAION occurs in patients with migraine and, as in those with optic disc drusen, tends to develop at an earlier age than does 'classic' NAION. No systematic study has been performed, but reported patients seem to be mainly under 50 years of age at onset, and many are in their 20s. ${ }^{56,57}$ Visual loss occurred during or immediately following an episode of cephalgia. The mechanism of vasculopathy has been postulated to be vasospasm. Katz and Bamford ${ }^{57}$ suggested that beta-blocking agents may potentiate this vasospastic effect in patients with complicated migraine, recommending avoidance of this class of drugs in this patient group.

Several medications have been associated with the development of NAION (Table 2). Interferon-alpha is a glycoprotein with antiviral, antitumour, and antiangiogenic effects used as adjuvant therapy for malignancies, including melanoma, leukaemia, and lymphoma, and for chronic hepatitis C. Several reports ${ }^{58-60}$ have confirmed the development of NAION, usually bilateral, sequential, and temporally associated with the institution of interferon therapy; recurrences with restarting the medication also have been described. The clinical course is variable, with some patients showing improvement with discontinuation of therapy. Possible pathogenetic mechanisms include interferon-induced systemic hypotension or immune complex deposition within the optic disc circulation.

Three drugs that inhibit phosphodiesterase 5-sildenafil (Viagra), tadalafil (Cialis), and vardenafil (Levitra)_are commonly prescribed for erectile dysfunction (ED). All three drugs may produce systemic hypotension; the therapeutic dose may reduce systemic blood pressure by at least $10 \mathrm{~mm} \mathrm{Hg}$. A number of cases of what appears to be NAION have been temporally associated with the use of these drugs. ${ }^{61}$ In addition, at least one 'challenge' case of NAION has been reported. ${ }^{62}$

Table 2 Drugs associated with the development of spontaneous NAION

\section{Interferon- $\alpha$}

Erectile dysfunction drugs

Amiodarone 
In all reported cases, the optic discs have had the typical 'crowded' configuration commonly seen in NAION. The postulated mechanism in these cases is systemic hypotension in patients with structurally predisposed optic discs, possibly complicated by an exaggerated nocturnal dip in blood pressure. Although the number of reported cases of NAION associated with the use of an ED drug is extremely small, particularly considering the widespread use of the drug, we agree with others that all male patients who develop NAION should be asked specifically and, ideally, in private, if they are using an ED drug. In addition, we recommend that patients for whom an ED drug is prescribed undergo an ophthalmologic examination and that if such patients have 'discs-at-risk,' they should be counselled regarding the risk of developing NAION if they used the drug.

Amiodarone is in widespread use as a cardiac antiarrhythmic agent and has been associated with the development of an anterior optic neuropathy that clinically mimics NAION. ${ }^{63-66}$ The problem in determining an association between amiodarone and NAION is that patients who are placed on amiodarone generally have severe cardiovascular disease as well as other vascular risk factors (eg, hyperlipidaemia and hypertension). Thus, they are already predisposed to developing spontaneous NAION. To clarify the association, Macaluso et $a l^{67}$ summarized the data from 73 patients, including 16 published case reports and 57 patients with information recorded in the National Registry of Drug-Induced Ocular Side Effects, with optic neuropathy associated with amiodarone use. These authors emphasized, as have Purvin et al, ${ }^{68}$ that those patients most likely to have an amiodarone-related NAION are those in which the condition is bilateral, has an insidious onset, and is characterized by generalized rather than altitudinal visual field loss as well as chronic optic disc swelling persisting months rather than weeks after onset of visual loss.

An interesting study was performed by Mindel et al $l^{69}$ in which 1669 subjects received either closed-label amidarone at a mean dose of $3.7 \mathrm{mg} / \mathrm{kg} /$ day $(n=837)$ or placebo $(n=832)$. All patients were followed for at least 27 months or until death (the median follow-up for survivors was 45.5 months). The end point of removal from the study was complaints of bilateral visual loss. In fact, no subject was removed from the study because of bilateral visual loss. Thus, the authors concluded that at commonly used doses, amiodarone infrequently produces bilateral visual loss if it does so at all. Having said this, it must be emphasized that the subjects in the study did not undergo routine ocular examinations and, thus, some patients may have experienced mild and asymptomatic visual dysfunction from amiodarone. In any event, we believe that, just as in the case of NAION associated with the use of ED drugs, any patient who develops NAION, particularly if it is bilateral and insidious in onset, should be asked specifically if he/she is taking amiodarone. If so, the patient as well as his/her cardiologist should be told of the possible association between the two, whereupon the decision to stop or continue the drug can be made by the patient and his/her physician. ${ }^{70}$

\section{Cellular mechanisms}

Recent advances in the understanding of ischaemic central nervous system damage have raised new questions regarding the pathogenesis of neuronal damage in both the arteritic and nonarteritic forms of AION. Neurotrophin deprivation in retinal ganglion cells after ischaemic insult may have a significant role in cell death. ${ }^{71,72}$ Secondary neuronal degeneration in cells adjacent to infarcted tissue may develop as a result of a toxic environment produced by the dying cells. ${ }^{73}$ Such deterioration may be mediated by processes including excitatory amino acid (especially glutamate) toxicity, reactive oxygen species (including lipid peroxidation), intracellular calcium influx, and apoptosis. ${ }^{20,74}$

Experimental models of optic nerve injury have been shown to be associated with elevated levels of glutamate in the overlying vitreous. ${ }^{75}$ Levin et $a l^{74}$ have shown evidence of apoptosis in the ganglion cells in a case of NAION. Thus, ischaemia-induced cell death may result in release of glutamate, with further cell damage and death by excitotoxic induction of apoptosis. The specific role each of these mechanisms may have in the development and clinical course of AION, however, remains unproven.

Unique animal models for optic nerve ischaemia that may provide a means to further study these aspects have recently been developed in rodents and in non-human primates. Bernstein et $a l^{76}$ selectively thrombosed the surface microvascular supply of the optic nerve in adult rats, using a photoablative technique. After intravenous infusion of the photosensitizing agent rose bengal, the optic nerve was exposed to a laser source, producing photoactivation of the intravascular agent, with selective damage of the endothelium by the superoxide radicals created in the exposed region, with resultant thrombosis. Cellular responses, including alterations in ganglion cell histopathology and retinal gene and protein expression, were studied and are consistent with other models of ischaemic neuronal injury. A mouse model of NAION subsequently was created by Goldenberg-Cohen et al ${ }^{77}$ and reproduced by Pangratz-Fuehrer et al. ${ }^{78}$ More recently, Chen et l $^{79}$ produced a non-human primate model of NAION in adult rhesus monkeys using the same basic technique. The primate model is similar to 
naturally occurring human NAION in clinical and fluorescein angiographic appearance (Figure 4) and is associated with electrophysiologic evidence of early optic nerve axon damage and delayed retinal ganglion cell loss (Figure 5), but there is no electrophysiological evidence of retinal dysfunction nor is there histological evidence of retinal damage other than thinning of the peripapillary retinal nerve fibre layer. Interestingly, histological and immunohistochemical assessments in all of these models indicates a significant inflammatory reaction in the region of the ischaemic lesion (Figures 6 and 7), suggesting that at least some of the optic nerve damage is related to inflammation rather than ischaemia. ${ }^{80,81}$ Even more importantly, a similar inflammatory reaction was found in an acute case of NAION studied histologically and immunohistochemically (Figures 8 and 9). ${ }^{81}$ Although the mechanism of production of ischaemic injury in these models differs from typical human NAION, the models nevertheless provide insight into the cellular mechanisms involved with ischaemic damage to ganglion cells and may be instrumental in testing future hypotheses for neuroprotective therapy in NAION.

\section{Clinical course}

Untreated, NAION generally remains stable, with most cases showing no significant improvement or deterioration over time. ${ }^{4,82-85}$ Even in the so-called progressive form, further deterioration after reaching the low point of visual function within 1-2 months is rare. ${ }^{4,86-88}$ Having said this,
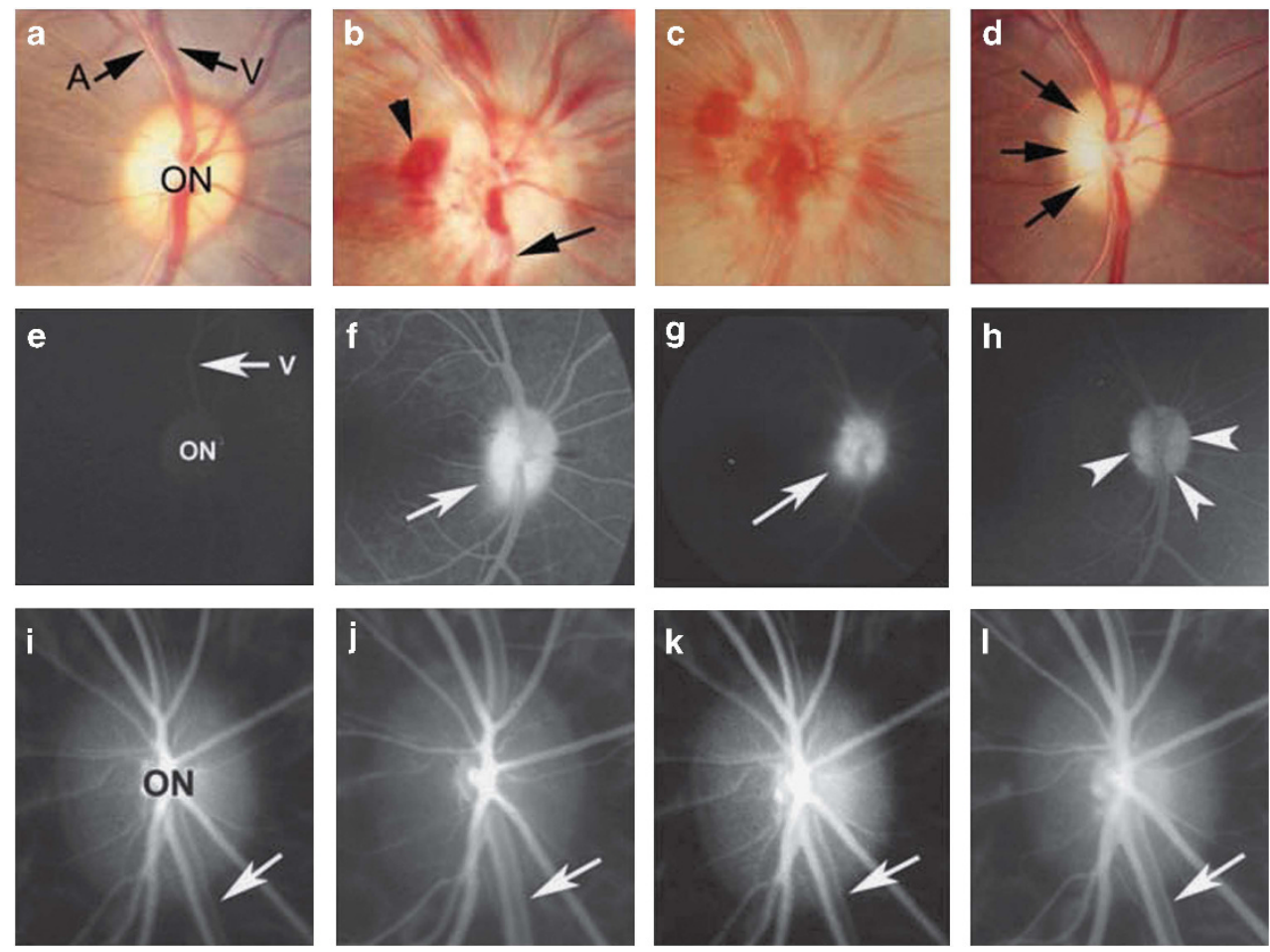

Figure 4 Clinical and angiographic findings in primate model of NAION (pNAION). (a-d) Optic disc colour photographs. (a) Before induction of pNAION, the optic disc $(\mathrm{ON})$ is normal in appearance, and the retinal arteries $(\mathrm{A})$ and veins $(\mathrm{V})$ are not obscured. Note that the disc has almost no central cup, thus mimicking a human 'disc-at -risk.' (b) Optic disc appearance 1-day post-induction. The disc is pale and swollen, with blurring of the retinal nerve fibre layer and obscuration of vessels as they cross the disc (arrow). Several peripapillary haemorrhages are present (arrowhead). (c) Seven days post-induction, optic disc oedema is increased and extensive haemorrhages overlie and surround the disc. (d) Seventy days post-induction, optic disc oedema has resolved and the disc is now pale, particularly temporally (arrows); the previously noted haemorrhages have also resolved. (e-h) Intravenous fluorescein angiography (IVFA) late phase (5-min post-dye injection). (e) Before induction. ON margins are sharply defined (arrowheads); there is no dye leakage. (f) Seven days post-induction, arteriovenous phase, there is generalized dye leakage from the optic disc, particularly from its temporal aspect (arrow). The margins of the disc are obscured. A peripapillary splinter haemorrhage is present at 3 o'clock. (g) Fourteen days post-induction, dye leakage persists and appears more generalized and the disc margins remain obscured (arrow). (h) Twenty-eight days post-induction, there is no dye leakage, only diffuse disc staining (arrowheads), suggesting re-establishment of an intact blood brain barrier. (i-1) High-resolution retinal ICG angiography (ICGA). (i) Before induction. The retina: ON border is sharply defined, and there is laminar blood flow in the veins (double arrowheads). Normal choroidal blood flow is definable by fine whitish streaks. (j) One-day post-induction. No disruption of either choroidal or intra-retinal blood flow is discernable. (k) Seven days post-induction. Choroidal and retinal blood flow remain intact. (l) Four weeks post-induction. There is no disruption of either retinal or choroidal blood flow; venous blood flow is laminar. (Reproduced with permission from Chen et al, ${ }^{79}$ copyright holder ARVO). 

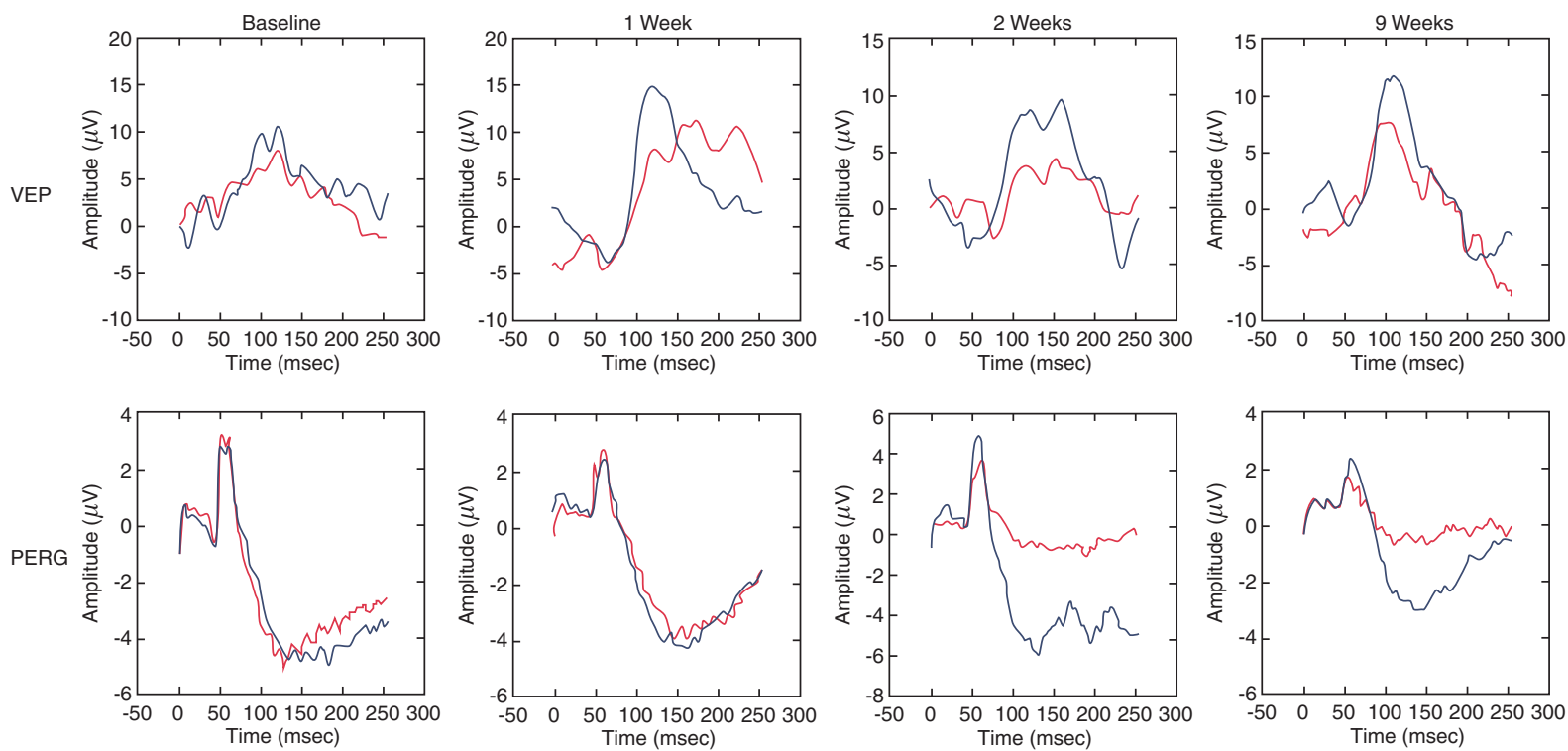

Figure 5 Clinical electrophysiology of control (blue lines) and 7-s pNAION-induced (red lines) eyes. The upper panel shows visual evoked potential (VEP) in both eyes at baseline (pre-induction), 1 week post induction, 2 weeks post induction, and 9 weeks post induction. At baseline, the VEPs are equal in the two eyes; however, at 1 week there is a reduction in the VEP amplitude from the pNAION eye, whereas the VEP amplitude in the control eye remains normal. The reduction in VEP amplitude in the pNAION eye persists at 2 and 9 weeks, whereas the VEP amplitude in the control eye remains normal. Note that the latency of the P100 peak remains normal in both eyes throughout the period of observation. The lower panel shows the pattern electroretinogram (PERG) of control and 7-s pNAION eyes during the same period as the VEP. At baseline, the PERG is normal in both eyes and remains normal in both eyes 1 week after induction; however, by 2 weeks post induction, there is a large reduction in the N95 PERG amplitude in the pNAION eye compared with the control eye, suggesting that intraocular retinal ganglion cell (RGC) function has declined following the optic nerve infarct. This reduction is still present at 9 weeks. The delay in PERG reduction suggests that, at least in this animal, RGC damage does not occur immediately. (Reproduced with permission from Chen et al, ${ }^{79}$ copyright holder ARVO).
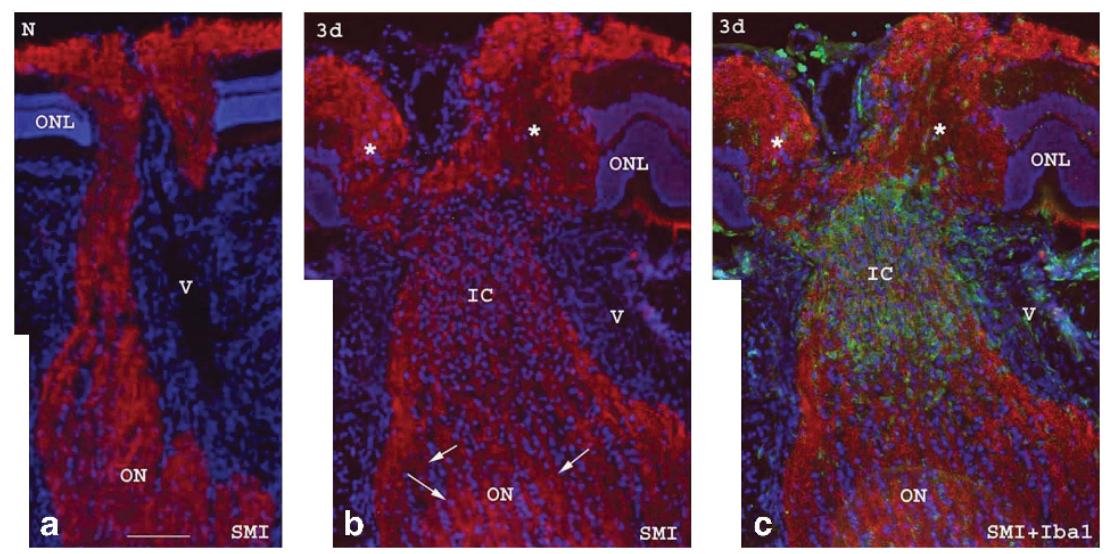

Figure 6 SMI312 (red) and Iba1 (green) immunolabelling of the optic nerve (ON) in a control ON (a) and in the optic nerve from an eye with rodent-induced anterior ischaemic optic neuropathy (rAION) 3 days after induction $(b, c)$. Sections are counterstained with Hoechst for the cell nuclei. (a) The normal ON shows intact neurofilaments characterized by intense SMI312 immunostaining in the anterior, intrascleral and retroscleral portions of the ON. (b, c) In a rAION-induced ON, SMI312 staining is intense in the anterior and retroscleral ON (arrows in b), but there is significant disruption of labelled neurofilaments in the axons in the intrascleral and immediate retroscleral portion of the ON (IC, ischaemic core in Figure b), with heavy infiltration of Iba1 $(+)$ macrophage/microglia (green in Figure c). This likely represents the ischaemic infarct region. Significant disc oedema $(*)$ is also noted in the anterior portion of the $\mathrm{ON}$ at 3-day after ischaemia. The juxtapapillary ONL layer is displaced laterally from the ON oedema caused by the infarct in the intrascleral and immediate retroscleral region. (ONL, outer nuclear layer; $\mathrm{V}$, blood vessel.) Bar $=50 \mu \mathrm{m}$. (Reproduced with permission from Zhang et $\left.a l^{80}\right)$. 

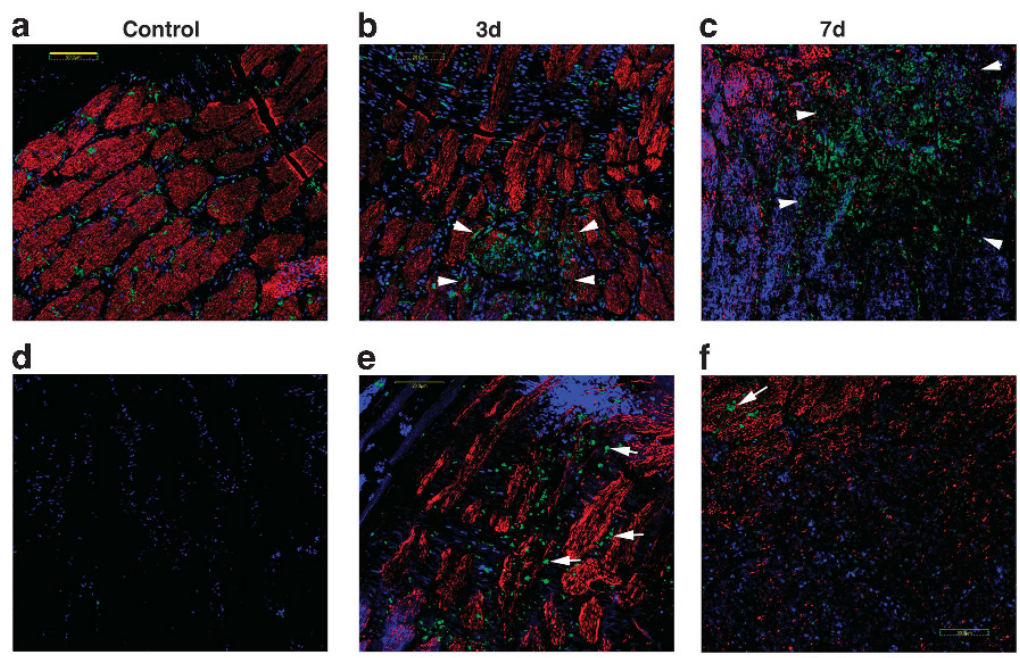

\section{g}

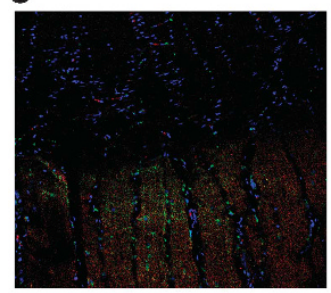

h

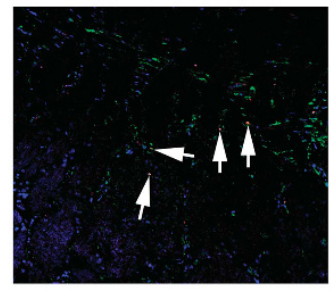

f

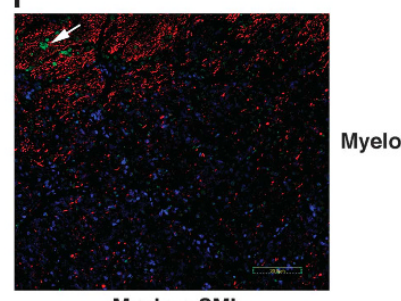

Myelo + SMI

i

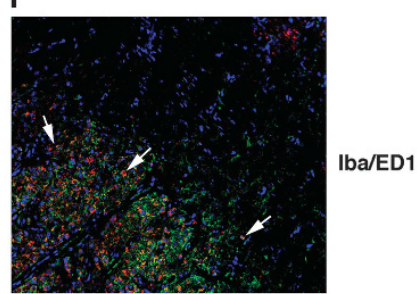

Figure 7 Identification of inflammatory cells in region of infarct shortly after induction of primate NAION (pNAION). (a, d, g) Control (naive) optic nerve (ON). (b, e, h) Three days post-induction. (c, f, i) Seven days post-induction. (a-c) Total inflammatory cell numbers. (a) The naive nerve has numerous Iba1 $(+)$ cells scattered throughout the ON structure, with normal axon numbers and staining. (b) Three days post-induction, there is focal Iba1 $(+)$ cell accumulation, with slight focal reduction of SMI312 immunopositivity. (c) One-week post-induction, there is marked loss of SMI312 immunopositivity, with increased focal accumulation of Iba1 (+) inflammatory cells. (d) In control nerve, few if any polymorphonuclear leukocytes (PMNs) are present. (e) Three days postinduction, PMNs are present as a focal accumulation in the region of ON damage. (f) PMN numbers are greatly decreased 1-week post-induction. (g) Few if any extrinsic macrophages (in red) are present in the naive ON, which has strong Iba1 $(+)$ cellular immunostaining. (h) Three days post-induction, there are a few Iba1 + )/ED1 ( +) cells (ie, extrinsic macrophages) in the affected ON region (arrows). (i) One-week post-induction, there are a large number of extrinsic macrophages (arrows) in the affected region. (Reproduced with permission from Salgado et $a l^{81}$ ).

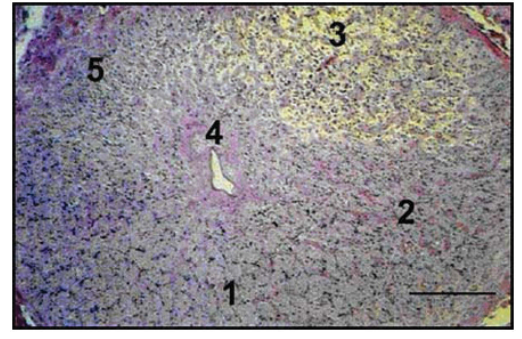

Figure 8 Cross-section of the affected optic nerve immediately posterior to the globe from a patient who died shortly after experiencing an attack of NAION, showing a large focal infarct (3) associated with axon loss; (haematoxylin and eosin, original magnification $\times 50$ ). Zone 1 is a grossly intact normal region of the NAION-affected $\mathrm{ON}$. Zones 2 and 5 are tissue areas adjacent to the infarct area (penumbral zone). Zone 3 represents the central infarct area. Zone 4 is the area adjacent to the infarct, which includes the central blood vessel that supplies the retina. (Reproduced with permission from Salgado et al ${ }^{81}$ ). it must be emphasized that spontaneous improvement of visual acuity is not unusual. Recovery of at least three Snellen acuity lines has been reported in up to $42.7 \%$ of patients, ${ }^{89}$ although significant improvement in visual field seems to occur less commonly than does improvement in acuity. ${ }^{90}$

After stabilization of vision, usually within 2-3 months, recurrent or progressive visual loss in an affected eye is extremely unusual and should prompt evaluation for another cause of optic neuropathy. Repka et $a l^{4}$ reported recurrent episodes in 3 of $83(3.6 \%)$ patients. Hayreh et al ${ }^{91}$ reviewed 829 eyes in 594 consecutive patients with NAION and documented recurrence in 53 eyes (6.4\%).

The initially swollen optic disc that occurs in acute NAION becomes pale, either sectorally or diffusely (Figure 10), usually within 6-11 weeks after onset of 

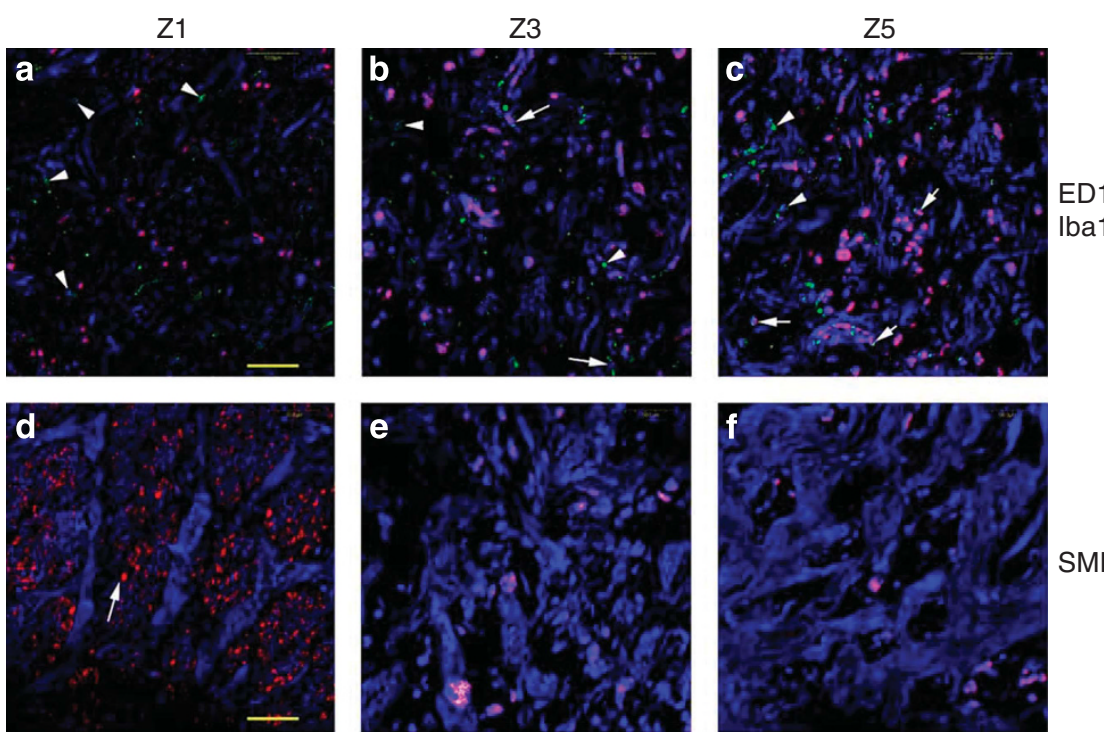

Figure 9 ED1(pink)), Iba1(green) SMI312 (red) immunostaining of a cross-section of human optic nerve 20 days after onset of visual loss from NAION. (a-c) ED1 and Iba1 immunostaining with DAPI counterstain. (e-f) SMI312 staining with DAPI counterstain. (a, d) Zone 1 (intact). (b, e) Zone 3 (presumed primary infarct region). (c, f) Zone 5 (presumed penumbral region). (a-c) Iba1(+)/ED1( - ) cells (ie, intrinsic microglia) are seen in all zones (arrowheads), but Iba1 $(+) / \operatorname{ED} 1(+)$ cells (ie, extrinsic macrophages) are present only in Zones 3 (b) and 5 (c). Specifically, no Iba1 $(+) / E D 1(+)$ cells are present in Zone 1 (a). (d) SMI312 staining in zone 1 reveals normal axon filaments. Filaments are absent or disrupted in zones $3(\mathrm{e})$ and 5 (f). Bar $=50 \mu \mathrm{m}$. (Reproduced with permission from Salgado et $\left.a l^{81}\right)$.
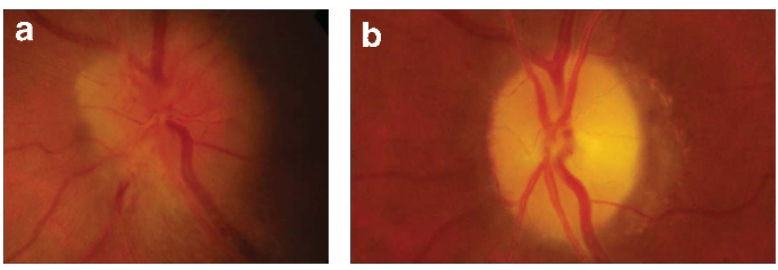

Figure 10 Appearance of NAION in the acute period (a) and 3 months later (b). Note progression from hyperaemic optic disc swelling in the acute phase to subsequent diffuse optic disc pallor.

visual loss. ${ }^{92}$ Persistence of swelling beyond this time frame should prompt consideration of an alternate diagnosis (eg, a compressive or infiltrative anterior optic neuropathy). Eventual involvement of the contralateral eye has been reported in $15-19 \%$ of patients within 5 years of initial eye involvement. ${ }^{93,94}$

Occurrence in the second eye produces the clinical appearance of a 'pseudo-Foster Kennedy syndrome,' in which the previously affected disc is pale and the currently affected disc is swollen. A history of acute visual loss in both eyes as well as significantly impaired visual function in the eye with the disc swelling distinguishes this condition from the true Foster Kennedy syndrome, in which there is no history of abrupt visual loss in the eye with the pale optic disc (the pallor is due to a compressive process) and the disc swelling in the contralateral eye oedema is due not to acute ischaemia but to elevated intracranial pressure and, therefore, is not associated with decreased vision (at least in the 'classical' syndrome).

Several authors have found that patients who develop NAION have a higher risk of subsequent cerebrovascular (eg, transient ischaemic events and strokes) and cardiovascular events (heart attacks) as well as an increased mortality from vascular events than a matched population. $3,6,82$

\section{Differential diagnosis}

NAION must be differentiated from other anterior optic neuropathies, including anterior optic neuritis (idiopathic, demyelinating, sarcoid-related, etc.), anterior compressive optic neuropathy (from anterior orbital lesions), and infiltrative optic neuropathy. Optic neuritis may resemble ischaemia with regard to rate of onset, pattern of visual field loss, and optic disc appearance; however, in most cases, the patient's younger age, pain with eye movement, and character of the disc swelling (diffuse and hyperaemic without haemorrhages, rather than pale or segmental) allow differentiation between the two conditions. Orbital lesions producing unilateral optic disc swelling usually produce gradually progressive visual loss. In addition, the detection of subtle signs of orbital disease, including mild proptosis, lid or eye movement abnormalities, or the persistence of optic disc swelling 
Table 3 NAION treatments attempted

Medical
Diphenylhydantoin
Aspirin
Corticosteroids
Systemic
Intravitreal
Anti-VEGF agents (eg, bevacizumab)
Erythropoietin/erythropoietin receptor agonists
Surgical
Optic nerve sheath fenestration
Optic neurotomy
Other
Hyperbaric oxygen

beyond the usual 6-11 weeks in NAION, may indicate the need to perform neuroimaging. Similarly, patients with infiltrative optic neuropathies such as those related to leukaemia, lymphoma, and sarcoid generally have either little visual loss or slowly progressive visual loss and chronic optic disc swelling.

\section{Diagnostic testing}

Perhaps the most important issues in diagnosing NAION are a careful medical and social history (including direct questioning regarding symptoms of OSA and giant cell arteritis (GCA) as well as use of ED drugs) followed by a complete examination. In patients with a typical presentation of NAION, without symptoms or signs suggesting GCA, and with normal erythrocyte sedimentation rate (ESR) and C-reactive protein (CRP) levels, we do not routinely perform additional testing. Indeed, in the appropriate setting, neither an ESR nor CRP may be needed. In all cases, however, an evaluation by a primary-care physician or internist for evidence and control of modifiable risk factors, such as hypertension, diabetes, hyperlipidaemia, obstructive sleep apnoea, and smoking, is essential. We do not perform neuroimaging unless the patient presents with substantial pain or follows an atypical course, such as prolonged optic disc swelling or continued progressive or recurrent visual loss $>2-3$ months after initial presentation. The value of additional testing for vasculopathic and prothrombotic risk factors remains unclear. We do not perform carotid studies unless prominent pain or other signs of orbital ischaemia are present. For NAION in the typical age group, we do not routinely assess homocysteine levels, but in patients under 50 , we perform this testing as elevated levels are amenable to therapy. We do not test for prothrombotic risk factors unless there is other evidence of personal or familial thrombosis or the patient is relatively young, and we do not screen for vasculitides other than GCA unless there is clinical evidence for them.
In patients with substantial hyperhomocysteinaemia, we recommend vitamin supplementation (B6, B12, and folic acid) and continued monitoring for evidence of systemic vasculopathy by a primary-care physician or an internist, although the value of lowering homocysteine levels for reduction of vascular events is unproven.

\section{Therapy}

There is no consistently effective therapy for NAION (Table 3). Diphenylhydantoin was assessed in a randomized controlled clinical trial and found to be ineffective, ${ }^{95}$ although it must be emphasized that subjects were treated 3 months after onset of visual loss so as to eliminate the potential for the natural history to be responsible for any visual improvement. There are no class I or class II data for the use of aspirin.

Hayreh and Zimmerman ${ }^{96}$ performed a nonrandomized, open-label trial of systemic corticosteroids for acute NAION and found some evidence that they were effective in improving visual function compared with the natural history; however, the untreated group had more vascular risk factors than the treated group. Although a subsequent randomized but much smaller trial by Rebolleda et $a l^{97}$ revealed no difference in visual outcome between treated and untreated subjects, we agree with Hayreh (personal communication) that the lack of efficacy of steroids in some (?many) cases of NAION may be related to the often delayed intervention and variations in severity of visual loss. Treatment with prednisone, beginning with a dose of $80 \mathrm{mg} /$ day and gradually reducing the dose over several weeks, probably is the most common treatment tried in patients with NAION.

Several investigators have reported small series in which treatment of acute NAION with an intravitreal injection of an anti-vascular endothelial growth factor (VEGF) agent such as bevacizumab was associated with an improved visual outcome; 98 however, a small nonrandomized prospective trial (17 patients treated and 8 patients not treated) failed to show any benefit in visual outcome or peripapillary retinal nerve fibre layer thickness between treated and non-treated subjects. ${ }^{99}$ In addition, several cases have been reported in which NAION developed shortly after an intravitreal injections of an anti-VEGF agent for age-related macular degeneration. ${ }^{100}$

Erythropoietin, a regulator of red blood cell production in response to hypoxaemia, is expressed by neurons, glial cells, and cerebrovascular endothelium, has been shown to be neuroprotective in vitro and in animal models of neuronal injury, ${ }^{101}$ and can be administered intravenously, intravitreally, or even topically. Modarres et al ${ }^{102}$ performed a small prospective trial in which $61 \%$ of 31 eyes treated with an intravitreal injection of erythropoietin 
experienced visual improvement; however, the vision in most of the eyes deteriorated after about 1 month.

In addition to medications, some investigators have tried other treatments for NAION. For example, Arnold et $a l^{103}$ treated 22 eyes in 20 patients with acute NAION using hyperbaric oxygen at 2.0 atmospheres twice a day for 10 days, comparing visual outcome to 27 untreated controls. These authors found no beneficial effect.

Optic nerve sheath fenestration (ONSF) is used to treat some cases of papilloedema with generally favourable results. The IONDT assessed the value of ONSF in the treatment of acute NAION based on the theory that at least some of the optic nerve damage caused by NAION in which there is progressive visual loss is due to post-ischaemic intraneural swelling with secondary impairment of local vascular flow or axoplasmic transport within the optic nerve head and that reduction of perineural subarachnoid cerebrospinal fluid pressure could improve vascular, axonal transport, or both, thus reducing tissue injury in reversibly damaged axons. Several earlier studies had suggested a beneficial effect in the progressive form of NAION. ${ }^{88,104,105}$ Recruitment for the IONDT was ceased after 2 years, with 119 treated and 125 untreated patients (most of whom had the non-progressive form of NAION!), when data analysis revealed no significant benefit of treatment. Indeed, improvement in visual acuity by at least three lines was noted in $32.6 \%$ of treated patients $v$ s $42.7 \%$ of untreated patients). ${ }^{89}$ Moreover, the treatment group showed a statistically significantly greater risk for worsening by three lines or more $(23.9 \%$ among treated patients vs $12.4 \%$ in untreated patients). There were too few subjects with progressive NAION in the trial to provide a definitive answer as to whether or not ONSF is beneficial in this setting; however, as there was a negative trend toward improvement in these subjects, this technique currently is not recommended for the treatment of either nonprogressive or progressive NAION.

Transvitreal optic neurotomy has been proposed as a therapy for NAION. The procedure involves a pars plana vitrectomy and induced posterior vitreous detachment, associated with a stab incision at the nasal margin of the optic disc, with the purpose of opening the scleral canal and relieving compression of an edematous optic nerve head. If a compartment syndrome is at least a component of the pathophysiology of NAION, such a procedure in theory could break the cycle of oedema and vascular compression. Soheilian et al ${ }^{106}$ reported the results of transvitreal neurotomy in patients with acute NAION and severe visual loss (visual acuity range counting fingers to 20/800) and onset before surgery ranging from 15 to 90 days. Improvement of visual acuity was noted in six patients, with a final range of counting fingers to 20/60.
This study was limited by several factors, including small patient numbers, sample bias (ie, severe visual loss with difficulty accurately measuring pre- and postoperative visual levels), and delayed onset of therapy. The authors emphasized the experimental nature of this procedure and recommended a randomized clinical trial before considering this approach.

\section{Prevention}

Just as there is no proven treatment for NAION, there is no proven prophylactic to prevent second-eye involvement. Although some authors have found evidence that aspirin can reduce the incidence of fellow-eye involvement after NAION, 107,108 a large retrospective review by Beck et al ${ }^{109}$ studied 431 patients with NAION for second-eye involvement with and without aspirin use. The 5-year risk for fellow-eye involvement was calculated at 12-19\%, depending on the analysis method, and no long-term benefit for aspirin use was found. The 5-year cumulative probability risk for fellow-eye NAION after the initial episode was $17 \%$ among treated patients vs $20 \%$ among untreated patients. A proposed prospective multicenter trial of aspirin to prevent second-eye involvement in patients with NAION was abandoned when it became clear that the number of subjects who would need to be recruited would be huge (about 2000) and would have to be followed for at least 5 years. In addition, there was concern that it would be impossible to keep subjects randomized to no treatment from being exposed to aspirin products. Nevertheless, although beneficial long-term effects remain unproven for NAION, many experts recommend the use of aspirin after an initial episode, if only for its role in decreasing risk for stroke and myocardial infarction in this vasculopathic population group.

In summary, we have learned much about the clinical manifestations, structural and vascular risk factors, and natural history of NAION; however, much remains to be learned about its pathogenesis, and a consistently effective therapy has yet to be identified.

\section{Conflict of interest}

The authors declare no conflict of interest.

\section{References}

1 Hattenhauer MG, Leavitt JA, Hodge DO, Grill R, Gray DT. Incidence of nonarteritic anterior ischemic optic neuropathy. Am J Ophthalmol 1997; 123: 103-107.

2 Johnson LN, Arnold AC. Incidence of nonarteritic and arteritic anterior ischemic optic neuropathy: population-based study in the State of Missouri and Los Angeles County, California. J Neuroophthalmol 1994; 14: $38-44$ 
3 Guyer DR, Miller NR, Auer CL, Fine SL. The risk of cerebrovascular and cardiovascular disease in patients with anterior ischemic optic neuropathy. Arch Ophthalmol 1985; 103: 1136-1142.

4 Repka MX, Savino PJ, Schatz NJ, Sergott RC. Clinical profile and long-term implications of anterior ischemic optic neuropathy. Am J Ophthalmol 1983; 96: 478-483.

5 Ischemic Optic Neuropathy Decompression Trial Research Group. Characteristics of patients with nonarteritic anterior ischemic optic neuropathy eligible for the Ischemic Optic Neuropathy Decompression Trial. Arch Ophthalmol 1996; 114: 1366-1374.

6 Hayreh SS, Joos KM, Podhajsky PA, Long CR. Systemic diseases associated with nonarteritic anterior ischemic optic neuropathy. Am J Ophthalmol 1994; 118: 766-780.

7 Hayreh SS, Podhajsky P, Zimmerman MB. Role of nocturnal arterial hypotension in optic nerve head ischemic disorders. Ophthalmologica 1999; 213: 76-96.

8 Swartz NG, Beck RW, Savino PJ, Sergott RC, Bosley TM, Lam BL et al. Pain in anterior ischemic optic neuropathy. J Neuroophthalmol 1995; 15: 9-10.

9 Hayreh SS, Podhajsky P. Visual field defects in anterior ischemic optic neuropathy. Doc Ophthalmol Proc Ser 1979; 19: 53-71.

10 Traustason OI, Feldon SE, Leemaster JE, Weiner JM. Anterior ischemic optic neuropathy: classification of field defects by Octopus automated static perimetry. Graefes Arch Clin Exp Ophthalmol 1988; 226: 206-212.

11 Rader J, Feuer WJ, Anderson DR. Peripapillary vasoconstriction in the glaucomas and the anterior ischemic optic neuropathies. Am J Ophthalmol 1994; 117: 72-80.

12 Jonas JB, Gusek GC, Naumann GO. Anterior ischemic optic neuropathy: nonarteritic form in small and giant cell arteritis in normal-sized optic discs. Int Ophthalmol 1988; 12: 119-125.

13 Mansour AM, Shoch D, Logani S. Optic disk size in ischemic optic neuropathy. Am J Ophthalmol 1988; 106 587-589.

14 Beck RW, Savino PJ, Repka MX, Schatz NJ, Sergott RC. Optic disc structure in anterior ischemic optic neuropathy. Ophthalmology 1984; 91: 1334-1337.

15 Beck RW, Servais GE, Hayreh SS. Anterior ischemic optic neuropathy. IX. Cup-to-disc ratio and its role in pathogenesis. Ophthalmology 1987; 94: 1503-1508.

16 Burde RM. Optic disk risk factors for nonarteritic anterior ischemic optic neuropathy. Am J Ophthalmol 1993; 116: 759-764.

17 Hayreh SS, Zimmerman MB. Incipient nonarteritic anterior ischemic optic neuropathy. Ophthalmology 2007; 114: 1763-1772.

18 Arnold AC, Costa RMS, Dumitrascu OM. The spectrum of optic disc ischemia in patients younger than 50 years. Trans Am Ophthalmol Soc 2013; 111: 93-118.

19 Arnold AC. Pathogenesis of nonarteritic anterior ischemic optic neuropathy. J Neuro-Ophthalmol 2003; 23: 157-163.

20 Kaup M, Plange N, Arend KO, Remky A. Retrobulbar haemodynamics in non-arteritic ischaemic optic neuorpathy. Br J Ophthalmol 2006; 90: 1350-1353.

21 Knox DL, Duke JR. Slowly progressive ischemic optic neuropathy. A clinicopathologic case report. Trans Am Acad Ophthalmol Otolaryngol 1971; 75: 1065-1068.
22 Levin LA, Louhab A. Apoptosis of retinal ganglion cells in anterior ischemic optic neuropathy. Arch Ophthalmol 1996; 114: 488-491.

23 Arnold AC, Hepler RS. Fluorescein angiography in acute nonarteritic anterior ischemic optic neuropathy. $A m$ J Ophthalmol 1994; 117: 222-230.

24 Levin LA, Danesh-Meyer HV. Hypothesis. A venous etiology for nonarteritic anterior ischemic optic neuropathy. Arch Ophthalmol 2008; 126: 1582-1585.

25 Tesser RA, Niendorf ER, Levin LA. The morphology of an infarct in nonarteritic anterior ischemic optic neuropathy. Ophthalmology 2003; 110: 2031-2035.

26 Knox DL, Kerrison JB, Green WR. Histopathologic studies of ischemic optic neuropathy. Trans Am Ophthalmol Soc 2000; 98: 203-222.

27 Hayreh SS, Zimmerman MB, Podhajsky P, Alward WL. Nocturnal arterial hypotension and its role in optic nerve head and ocular ischemic disorders. Am J Ophthalmol 1994; 117: 603-624.

28 Landau K, Winterkorn JMS, Mailloux LU, Vetter W, Napolitano B. 24-Hour blood pressure monitoring in patients with anterior ischemic optic neuropathy. Arch Ophthalmol 1996; 114: 570-575.

29 Jacobson DM, Vierkant RA, Belongia EA. Nonarteritic anterior ischemic optic neuropathy. A case-control study of potential risk factors. Arch Ophthalmol 1997; 115: 1403-1407.

30 Salomon O, Huna-Baron R, Kurtz S, Steinberg DM, Moisseiev J, Rosenberg $\mathrm{N}$ et al. Analysis of prothrombotic and vascular risk factors in patients with nonarteritic anterior ischemic optic neuropathy. Ophthalmology 1999; 106: 739-742.

31 Lee MS, Grossman D, Arnold AC, Sloan FA. Incidence of nonarteritic anterior ischemic optic neuropathy: increased risk among diabetic patients. Ophthalmology 2011; 118: 959-963.

32 Talks SJ, Chong NH, Gibson JM, Dodson PM. Fibrinogen, cholesterol, and smoking as risk factors for non-arteritic anterior ischaemic optic neuropathy. Eye 1995; 9: 85-88.

33 Deramo VA, Sergott RC, Augsburger JJ, Foroozan R, Savino PJ, Leone A. Ischemic optic neuropathy as the first manifestation of elevated cholesterol levels in young patients. Ophthalmology 2003; 110: 1041-1045.

34 Chung SM, Gay CA, McCrary JA. Nonarteritic anterior ischemic optic neuropathy. The impact of tobacco use. Ophthalmology 1994; 101: 779-782.

35 Mojon DS, Hedges 3rd TR, Ehrenberg B, Karam EZ, Goldblum D, Abou-Chebl A et al. Association between sleep apnea syndrome and nonarteritic anterior ischemic optic neuropathy. Arch Ophthalmol 2002; 120: 601-605.

36 Polombi K, Renard E, Levy P, Chiquet C, Ch Deschaux, Romanet JP et al. Non-arteritic anterior ischemic optic neuropathy is nearly systematically associated with obstructive sleep apnoea. Br J Ophthalmol 2006; 90: 879-882.

37 Li J, McGwin Jr G, Vaphiades MS, Owsley C. Non-arteritic anterior ischaemic optic neuropathy and presumed sleep apnoea syndrome screened by the Sleep Apnea scale of the Sleep Disorders Questionnaire (SA-SDQ). Br J Ophthalmol 2007; 91: 1524-1527.

38 Bilgin G, Koban Y, Arnold AC. Nonarteritic anterior ischemic optic neuropathy and obstructive sleep apnea. J Neuroophthalmol 2013; 33: 232-234.

39 Stein JD, Kim DS, Mundy KM, Talwar N, Nan B, Chervin RD et al. The association between glaucomatous 
and other causes of optic neuropathy and sleep apnea. Am J Ophthalmol 2011; 152: 989-998.

40 Kolb SD, Backhouse O. Obstructive sleep apnoea prevalence in non-arteritic anterior ischaemic optic neuropathy: a response. Br J Ophthalmol 2013; 97: 794.

41 Arda H, Birer S, Aksu M, Ismailogullari S, Karakucuk S, Mirza E et al. Obstructive sleep apnoea prevalence in non-arteritic anterior ischaemic optic neuropathy. Br J Ophthalmol 2013; 97: 206-209.

42 Behbehani R, Mathews MK, Sergott RC, Savino PJ. Nonarteritic anterior ischemic optic neuropathy in patients with sleep apnea while being treated with continuous positive airway pressure. Am J Ophthalmol 2005; 139: 518-521.

43 Pianka P, Almog Y, Man O, Goldstein M, Sela BA, Loewenstein A. Hyperhomocysteinemia in patients with nonarteritic anterior ischemic optic neuropathy, central retinal artery occlusion, and central retinal vein occlusion. Ophthalmology 2000; 107: 1588-1592.

44 Weger M, Stanger O, Deutschmann H, Simon M, Renner W, Schmut O et al. Hyperhomocysteinemia, but not MTHFR C677T mutation, as a risk factor for non-arteritic anterior ischaemic optic neuropathy. Br J Ophthalmol 2001; 85: 803-806.

45 Biousse V, Kerrison JB, Newman NJ. Is non-arteritic anterior ischaemic optic neuropathy related to homocysteine? Br J Ophthalmol 2000; 84: 554.

46 Salomon O, Dardik R, Steinberg DM, Kurtz S, Rosenberg N, Moisseiev $\mathrm{J}$ et al. The role of angiotensin converting enzyme and angiotensin II type 1 receptor gene polymorphisms in patients with nonarteritic anterior ischemic optic neuropathy. Ophthalmology 2000; 107: 1717-1720.

47 Salomon O, Rosenberg N, Steinberg DM, Huna-Baron R, Moisseiev J, Dardik R et al. Nonarteritic anterior ischemic optic neuropathy is associated with a specific platelet polymorphism located on the glycoprotein $\mathrm{Ib}$-alpha gene. Ophthalmology 2004; 111: 184-188.

48 Purvin V, King R, Kawasaki A, Yee R. Anterior ischemic optic neuropathy in eyes with optic disc drusen. Arch Ophthalmol 2004; 122: 48-53.

49 Townes CD, Moran CT, Pfingst HA. Complications of cataract surgery. Trans Am Acad Ophthalmol 1951; 49: 91-107.

50 Reese AB, Carroll FD. Optic neuritis following cataract extraction. Am J Ophthalmol 1958; 45: 659-662.

51 Michaels DD, Zugsmith GS. Optic neuropathy following cataract extraction. Ann Ophthalmol 1973; 5: 303-306.

52 Carroll FD. Optic nerve complications of cataract extraction. Tr Am Acad Ophthalmol Otolaryngol 1973; 77: OP623-OP629.

53 McCulley TJ, Lam BL, Feuer WJ. Incidence of nonarteritic anterior ischemic optic neuropathy associated with cataract extraction. Ophthalmology 2001; 108: 1275-1278.

54 McCulley TJ, Lam BL, Feuer WJ. Nonarteritic anterior ischemic optic neuropathy and surgery of the anterior segment: temporal relationship analysis. Am J Ophthalmol 2003; 136: 1171-1172.

55 Lam BL, Jabaly-Habib H, Al-Sheikh N, Pezda M, Guirgis MF, Feuer WJ et al. Risk of non-arteritic anterior ischaemic optic neuropathy (NAION) after cataract extraction in the fellow eye of patients with prior unilateral NAION. Br J Ophthalmol 2007; 91: 585-587.

56 McDonald WI, Sanders MD. Migraine complicated by ischaemic papillopathy. Lancet 1971; 2: 521-523.
57 Katz B, Bamford CR. Migrainous ischemic optic neuropathy. Neurology 1985; 35: 112-114.

58 Purvin VA. Anterior ischemic optic neuropathy secondary to interferon alpha. Arch Ophthalmol 1995; 113: 1041-1044.

59 Gupta R, Singh S, Tang R, Blackwell TA, Schiffman JS. Anterior ischemic optic neuropathy caused by interferon alpha therapy. Am J Med 2002; 112: 683-684.

60 Vardizer Y, Linhart Y, Loewenstein A, Garzozi H, Mazawi N, Kesler A. Interferon-alpha-associated bilateral simultaneous ischemic optic neuropathy. J Neuroophthalmol 2003; 23: 256-259.

61 Pomeranz HD, Smith KH, Hart Jr WM, Egan RA. Sildenafil-associated nonarteritic anterior ischemic optic neuropathy. Ophthalmology 2002; 109: 584-587.

62 Bollinger K, Lee MS. Recurrent visual field defect and ischemic optic neuropathy associated with tadalafil rechallenge. Arch Ophthalmol 2005; 123: 400-401.

63 Gittinger Jr JW, Asdourian GK. Papillopathy caused by amiodarone. Arch Ophthalmol 1987; 105: 349-351.

64 Feiner LA, Younge BR, Kazmier FJ, Stricker BH, Fraunfelder FT. Optic neuropathy and amiodarone therapy. Mayo Clin Proc 1987; 62: 702-717.

65 Palimar P, Cota N. Bilateral anterior ischaemic optic neuropathy following amiodarone. Eye 1998; 12: 894-896.

66 Seemongal-Dass RR, Spencer SR. Bilateral optic neuropathy linked with amiodarone. Eye 1998; 12: 474-477.

67 Macaluso DC, Shults WT, Fraunfelder FT. Features of amiodarone-induced optic neuropathy. Am J Ophthalmol 1999; 127: 610-612.

68 Purvin V, Kawasaki A, Borruat FX. Optic neuropathy in patients using amiodarone. Arch Ophthalmol 2006; 124: 696-701.

69 Mindel JS, Anderson J, Hellkamp A, Johnson G, Poole JE, Mark DB et al. Absence of bilateral vision loss from amiodarone: a randomized trial. Am Heart J 2007; 153: 837-842.

70 Murphy MA, Murphy JF. Amiodarone and optic neuropathy: the heart of the matter. J Neuroophthalmol 2005; 25: 232-236.

71 Quigley HA, McKinnon SJ, Zack DJ, Pease ME, Kerrigan-Baumrind LA, Kerrigan DF et al. Retrograde axonal transport of BDNF in retinal ganglion cells is blocked by acute IOP elevation in rats. Invest Ophthalmol Vis Sci 2000; 41: 3460-3466.

72 Mansour-Robaey S, Clarke DB, Wang YC, Bray GM, Aguayo AJ. Effects of ocular injury and administration of brain-derived neurotrophic factor on survival and regrowth of axotomized retinal ganglion cells. Proc Natl Acad Sci USA 1994; 91: 1632-1636.

73 Sucher NJ, Lipton SA, Dreyer EB. Molecular basis of glutamate toxicity in retinal ganglion cells. Vision Res 1997; 37: 3483-3493.

74 Levin LA, Clark JA, Johns LK. Effect of lipid peroxidation inhibition on retinal ganglion cell death. Invest Ophthalmol Vis Sci 1996; 37: 2744-2749.

75 Vorwerk CK, Zurakowski D, McDermott LM, Mawrin C, Dreyer EB. Effects of axonal injury on ganglion cell survival and glutamate homeostasis. Brain Res Bull 2004; 62: 485-490.

76 Bernstein SL, Guo Y, Kelman SE, Flower RW, Johnson MA. Functional and cellular responses in a novel rodent model 
of anterior ischemic optic neuropathy. Invest Ophthalmol Vis Sci 2003; 44: 4153-4162.

77 Goldenberg-Cohen N, Guo Y, Margolis F, Cohen Y, Miller NR, Bernstein SL. Oligodendrocyte dysfunction after induction of experimental anterior optic ischemia. Invest Ophthalmol Vis Sci 2005; 46: 2716-2725.

78 Pangratz-Fuehrer S, Kaur K, Ousman SS, Steinman L, Liao YJ. Functional rescue of experimental ischemic optic neuropathy with $\alpha \mathrm{B}$-crystallin. Eye 25: 809-817.

79 Chen CS, Johnson MA, Flower RA, Slater BJ, Miller NR, Bernstein SL. A primate model of nonarteritic anterior ischemic optic neuropathy. Invest Ophthalmol Vis Sci 2008; 49: 2985-2992.

80 Zhang C, Guo Y, Miller NR, Bernstein SL. Optic nerve infarction and post-ischemic inflammation in the rodent model of anterior ischemic optic neuropathy (rAION). Brain Res 2009; 1264: 67-75.

81 Salgado C, Vilson F, Miller NR, Bernstein SL. Cellular inflammation in nonarteritic anterior ischemic optic neuropathy and its primate model. Arch Ophthalmol 2011; 129: 1583-1591.

82 Sawle GV, James CB, Ross Russell RW. The natural history of nonarteritic anterior ischaemic optic neuropathy. J Neurol Neurosurg Psychiatry 1990; 53: 830-833.

83 Arnold AC, Hepler RS. Natural history of nonarteritic anterior ischemic optic neuropathy. J Neuroophthalmol 1994; 14: 66-69.

84 Movsas T, Kelman SE, Elman MJ, Miller NR. The natural course of non-arteritic ischemic optic neuropathy. Invest Ophthalmol Vis Sci 1991; 32(Suppl): 951.

85 Ischemic Optic Neuropathy Decompression Trial Research Group. Twenty-four month update. Arch Ophthalmol 2000; 118: 793-798.

86 Borchert M, Lessell S. Progressive and recurrent nonarteritic anterior ischemic optic neuropathy. Am J Ophthalmol 1988; 106: 443-449.

87 Kline LB. Progression of visual defects in ischemic optic neuropathy. Am J Ophthalmol 1988; 106: 199-203.

88 Sergott RC, Cohen MS, Bosley TM, Savino PJ. Optic nerve sheath decompression may improve the progressive form of ischemic optic neuropathy. Arch Ophthalmol 1989; 107: 1743-1754.

89 Ischemic Optic Neuropathy Decompression Trial Research Group. Optic nerve decompression surgery for nonarteritic anterior ischemic optic neuropathy (NAION) is not effective and may be harmful. JAMA 1995; 273: 625-632.

90 Scherer RW, Feldon SE, Levin L, Langenberg P, Katz J, Keyl PM et al. Visual fields at follow-up in the Ischemic Optic Neuropathy Decompression Trial: evaluation of change in pattern defect and severity over time. Ophthalmology 2008; 115: 1809-1817.

91 Hayreh SS, Podhajsky PA, Zimmerman B. Ipsilateral recurrence of nonarteritic anterior ischemic optic neuropathy. Am J Ophthalmol 2001; 132: 734-742.

92 Hayreh SS, Zimmerman MB. Optic disc edema in non-arteritic anterior ischemic optic neuropathy. Graefes Arch Clin Exp Ophthalmol 2007; 245: 1107-1121.

93 Beck RW, Hayreh SS, Podhajsky PA, Tan ES, Moke PS. Aspirin therapy in nonarteritic anterior ischemic optic neuropathy. Am J Ophthalmol 1997; 123: 212-217.

94 Newman NJ, Scherer R, Langenberg P, Kelman S, Feldon S, Kaufman $\mathrm{D}$ et al. The fellow eye in NAION: report from the Ischemic Optic Neuropathy Decompression Trial follow-up study. Am J Ophthalmol 2002; 134: 317-328.

95 Keltner JL, Becker B, Gay AJ, Podos SM. Effect of diphenylhydantoin in ischemic optic neuritis. Trans Am Ophthalmol Soc 1972; 70: 113-128.

96 Hayreh SS, Zimmerman MB. Non-arteritic anterior ischemic optic neuropathy: role of systemic corticosteroid therapy. Graefes Arch Clin Exp Ophthalmol 2008; 246: 1029-1046.

97 Rebolleda G, Pérez-López M, Casas-Llera P, Muñoz-Negrete FJ. Treatment of non-arteritic anterior ischemic optic neuropathy with high-dose systemic corticosteroids. Graefes Arch Clin Exp Ophthalmol 2013; 251: 1031-1032.

98 Bennett JL, Thomas S, Olson JL, Mandava N. Treatment of nonarteritic anterior ischemic optic neuropathy with intravitreal bevacizumab. J Neuroophthalmol 2007; 27: 238-240.

99 Rootman D, Gill HS, Margolin EA. Intravitreal bevacizumab for the treatment of nonarteritic anterior ischemic optic neuropathy: a prospective trial. Eye 2013; 27: 538-544

100 Mansour AM, Shahin M, Kofoed PK, Parodi MB, Shami M, Schwartz SG et al. Insight into 144 patients with ocular vascular events during VEGF antagonist injections. Clin Ophthalmol 2012; 6: 343-363.

101 Pankratova S, Kiryushko D, Sonn K, Soroka V, Køhler LB, Rathje $\mathrm{M}$ et al. Neuroprotective properties of a novel, non-haematopoietic agonist of the erythropoietin receptor. Brain 2010; 133: 2281-2294.

102 Modarres M, Falavarjani KG, Nazari H, Sanjari MS, Aghamohammadi F, Homaii $\mathrm{M}$ et al. Intravitreal erythropoietin injection for the treatment of non-arteritic anterior ischaemic optic neuropathy. Br J Ophthalmol 2011; 95: 992-995.

103 Arnold AC, Hepler RS, Lieber M, Alexander JM. Hyperbaric oxygen therapy for nonarteritic anterior ischemic optic neuropathy. Am J Ophthalmol 1996; 122: 535-541.

104 Spoor TC, Wilkinson MJ, Ramocki JM. Optic nerve sheath decompression for the treatment of progressive nonarteritic ischemic optic neuropathy. Am J Ophthalmol 1991; 111: 724-728.

105 Kelman SE, Elman MJ. Optic nerve sheath decompression for nonarteritic anterior ischemic optic neuropathy improves multiple visual function measurements. Arch Ophthalmol 1991; 109: 667-671.

106 Soheilian M, Koochek A, Yazdani S, Peyman GA. Transvitreal optic neurotomy for nonarteritic anterior ischemic optic neuropathy. Retina 2003; 23: 692-697.

107 Kupersmith MJ, Frohman L, Sanderson M, Jacobs J, Hirschfeld J, Ku C et al. Aspirin reduces the incidence of second eye NAION: a retrospective study. $J$ Neuroophthalmol 1997; 17: 250-253.

108 Salomon O, Huna-Baron R, Steinberg DM, Kurtz S, Seligsohn U. Role of aspirin in reducing the frequency of second eye involvement in patients with non-arteritic anterior ischaemic optic neuropathy. Eye 1999; 13: 357-359.

109 Beck RW, Hayreh SS. Role of aspirin in reducing the frequency of second eye involvement in patients with non-arteritic anterior ischaemic optic neuropathy. Eye 2000; 14: 118. 